\title{
Sepsis from Neurofibromatosis
}

\author{
Navdeep Tangri, Shireen Sirhan, Gordon Crelinsten
}

Can. J. Neurol. Sci. 2006; 33: 328

Neurofibromatosis Type I or von Recklinghausen's neurofibromatosis is an autosomal dominant disorder with a high index of spontaneous mutations and extremely varied and unpredictable clinical manifestations. We present a case of sepsis secondary to an infected hematoma, enclosed within a massive neurofibroma.

A 42-year-old man presented to the emergency department with a one week history of fever and chills. He reported an increase in pain and size of a growth near his chest. The patient was noted to be febrile on arrival. On physical examination, a very large neurofibroma was seen extending from the right upper chest. Wound and blood cultures were obtained. Computed Tomography (CT) of the thorax revealed a hematoma contained within the large mass.

Wound cultures grew coagulase negative staphylococci and pseudomonas species. The patient was treated with intravenous

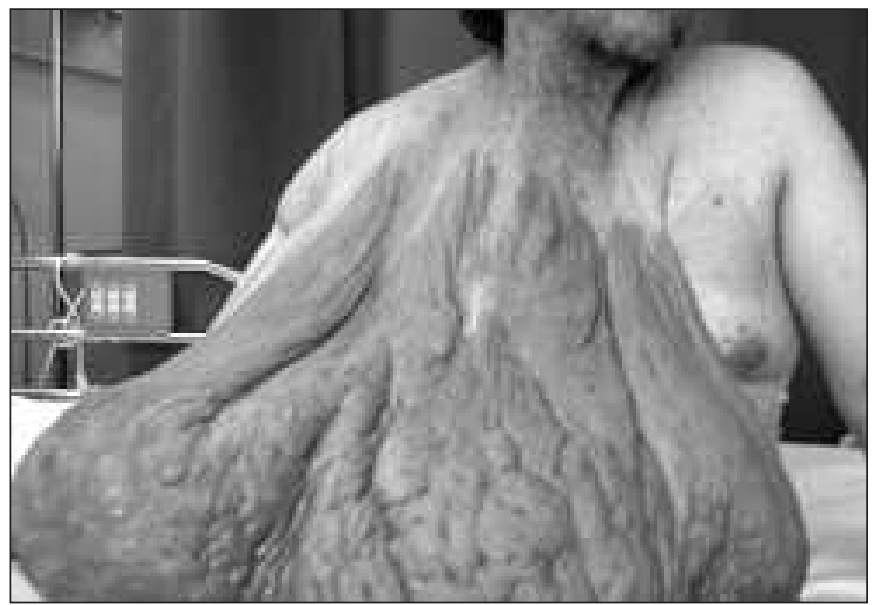

vancomycin and ceftriaxone. Resolution of fever was noted on Day 5 post admission. The patient was referred to plastic surgery and underwent successful excision of a 44 pound mass. After a prolonged ICU stay, the patient made a complete recovery and was well at a six month follow-up.

The NF1 gene, isolated in 1990, is a large gene spanning over $350 \mathrm{~kb}$ of genomic DNA, mapping to chromosome $17 \mathrm{q} 11 \cdot 2$. It encodes a protein containing 2818 aminoacids named neurofibromin, which has a role in tumour suppression. ${ }^{1}$ The

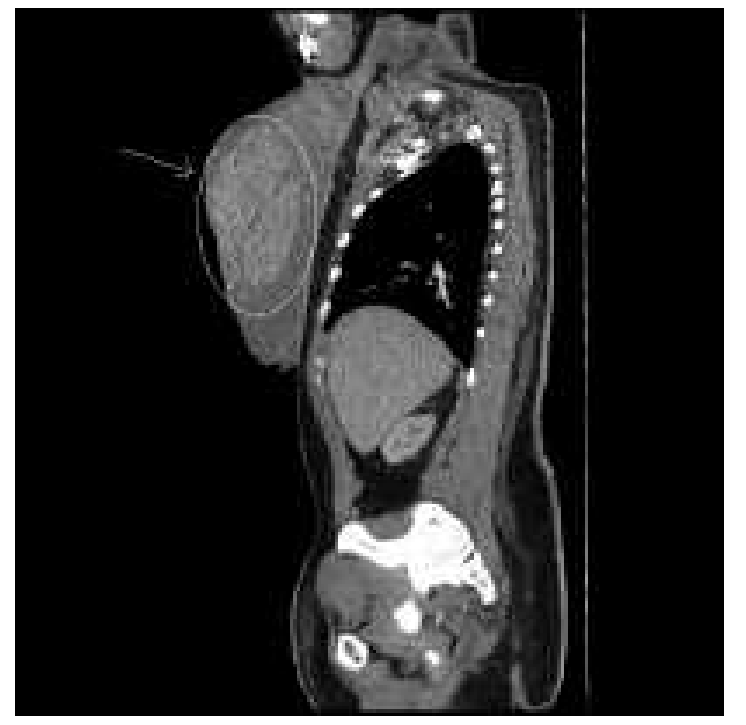

typical characteristic of neurofibromatosis type 1 is the neurofibroma. These tumours represent the major cause of morbidity and death; they affect long portions of nerves, infiltrate the nerve and surrounding tissue, resulting in widespread disfiguration and mechanical complications. Treatment by excision of these tumours is therefore important to prevent infectious and malignant complications. ${ }^{2}$

\section{REFERENCES}

1. Reynolds RM, Browning GG, Nawroz I, Campbell IW. Von Recklinghausen's neurofibromatosis: neurofibromatosis type 1. Lancet. 2003 May 3;361(9368):1552-4.

2. Arun D, Gutmann DH. Recent advances in neurofibromatosis type 1. Curr Opin Neurol. 2004 Apr;17(2):101-5.

From the Department of Internal Medicine, McGill University, Montreal, Quebec, Canada.

ReCeived December 6, 2005. ACCEPTED in FinAl Form April 22, 2006. Reprint requests to: Navdeep Tangri, Department of Internal Medicine, McGill University, 1209 - 4870 Ch Cote Des Neiges, Montreal, Quebec, H3V 1H3, Canada. 